\title{
Monetary Union Expansion: The Role of Market Power in Trade*
}

\author{
Mark M. Spiegel ${ }^{\dagger}$
}

March 3, 2000

\begin{abstract}
This paper examines the feasibility of a monetary union expansion which is desirable for both the entering country and the existing union members. The paper concentrates on the fact that the outside country is likely to be small relative to the existing monetary union, and lack the resistance to inflation which comes with market power in trade. Consideration of this market power effect allows for mutually-desirable entry if the outside nation central bank is moderately more averse to inflation than the central bank of the existing monetary union.
\end{abstract}

J.E.L. Classification numbers F33, F36

*I thank without implicating Ken Kasa, Philip Lane, and Andrew Rose for helpful comments. Remaining errors are my own. The opinions in this paper do not necesssarily reflect those of the Federal Reserve Bank of San Francisco or the Federal Reserve System.

${ }^{\dagger}$ Federal Reserve Bank of San Francisco, 101 Market St., San Francisco, CA, 94105, Mark.Spiegel@sf.frb.org. 


\section{Introduction}

There is a large literature on the benefits and costs of the formation of a monetary union. ${ }^{1}$ Among the reasons for joining a monetary union, the literature has stressed the potential for improvement in the credibility of a nation's monetary regime. The argument loosely goes that a high-inflation nation can gain credibility, and perhaps welfare, by joining a monetary union dominated by nations which prefer lower inflation rates. In this paper, I examine such an argument for an outside country deciding whether or not to join an existing monetary union. Such a decision will soon be faced by some of the so-called "out nations" of the European Community.

As in Casella [10, (1992)], I concentrate on the requirement that an outside nation will join an existing monetary union only if its joining is in the mutual interest of both the outside nation and its existing members. The analysis below demonstrates that the enhanced credibility argument for joining a monetary union is unlikely to succeed when the outside country is given a non-trivial voice in monetary policy subsequent to joining. The intuition is that entry by any country whose credibility would be enhanced by joining a monetary union would reduce the credibility of the union as a whole. In other words, solely on credibility considerations, an outside country would not be accepted into a union it wished to join.

To motivate the outside country being allowed to join the monetary union, then, other potential gains must be considered. This paper concentrates on the fact that an outside country is likely to be quite small relative to an existing mon-

\footnotetext{
${ }^{1}$ See, for example, Bean [6, (1992)] and Wyplosz [18, (1997)].
} 
etary union. As I show below, this asymmetry affects the impact of entry by the outside country. When the outside country is small and an export competitor of the existing monetary union, its entry may change the predisposition of monetary policy in the union towards inflation without affecting the impact of monetary policy within the union on its real exchange rate. As a result, it becomes possible that both the outside country and the existing members of the monetary union may enjoy a reduction in inflation due to entry by the outside country.

The modeling strategy used in the paper is a simple Barro-Gordon [3, (1983)] static framework in which the central bank faces a time-consistency problem in the choice of its nominal exchange rate depreciation. Given nominal wage rates, central banks are inclined to depreciate their currencies more rapidly in an effort to increase output ex-post through expenditure-switching. They obtain an interior solution for the amount of depreciation they choose based on their desire to raise domestic output and their aversion to inflation. ${ }^{2}$

To keep the analysis simple, I do not model the welfare implications of such a decrease in the rate of nominal exchange rate depreciation. However, I consider such a reduction likely to be welfare increasing, as would be the case in an environment in which nominal wages were contractually fixed, but agents possessed rational expectations. Rational agents, anticipating the central bank's inability to resist increasing the rate of nominal exchange rate depreciation to pursue its output goals, negotiate wage contracts which leave monetary policy neutral. The

\footnotetext{
${ }^{2}$ We do not address the possibility that the outside country may pursue a unilateral peg to escape its credibility problem. It has been argued inthe literature that the credibility of such unilateral pegs may be limited [Obstfeld [16, (1997)], Bergin and Moersch [7, (1997)]]. Obstfeld $[16,(1997)]$ notes the explicit understanding that if an ERM2 is constructed interventions may cease if they threaten price stability.
} 
net result of increased depreciation is then only the loss from inflation.

Such a framework has been applied to monetary policy coordination problems, and to EMU in particular, by Rogoff [17, (1985)], Canzoneri and Henderson [8, (1991)] and Alesina and Grilli [1, (1991)],[2, (1993)], among others. As in Rogoff $[17,(1985)]$, because the existing monetary union is large in our model, the output effect of a given dose of depreciation is mitigated by the adverse terms of trade effect associated with an increase in the output of the monetary union. This reduces the overall rate of depreciation chosen by the monetary union. However, because the outside country is small, it faces no such deterrence and, holding all else equal, chooses a higher rate of depreciation. Again, holding all else equal, by joining the monetary union the outside country shares in the desirable feature that a large monetary regime has a real exchange rate distortion which partially offsets its incentives to inflate.

The results below demonstrate that this disparity in market power can facilitate mutually-desirable entry by the outside nation into the monetary union. In particular, I identify two characteristics necessary for mutually-desirable entry by the outside nation: First, the outside nation must be more inflation-averse than the central bank of the existing monetary union. Second, the outside nation must be sufficiently similar in its attitude towards inflation to the central bank of the existing monetary union.

There are other characteristics which may affect the welfare implications of a nation joining a monetary union which I do not address here. First, I examine a deterministic model, which omits the implications of a monetary union for a country's ability to deal with nation-specific shocks. As a result, the analysis completely ignores the motivation an outside country may have to join a mone- 
tary union for optimal currency area considerations. ${ }^{3}$ Obstfeld [16, (1997)] notes that asymmetry in exposure to shocks can certainly be expected in the European Monetary Union, such as Germany's greater exposure to Eastern Europe. Second, I do not consider the fiscal implications of monetary union, as in Canzoneri and Rogers [9, (1990)] or Cooper and Kempf [12, (1998)]. Third, I assume that the rules of the existing monetary union are invariant to the entry choice of the outside country. This rules out the possibility that transfers may emerge through the bargaining process over the terms of entry. Chang [11, (1995)] argues that such transfers can emerge from the bargaining process over the formation of a monetary union. Fourth, the model does not include a non-tradable sector. Lane $[13,(1997)]$ has shown that imperfect competition and nominal price rigidity can combine to influence relative inflation biases under different stages of "openness," even if economies are small. Fifth, I do not confront the relative desirability of an outside country joining the union initially. Martin [15, (1995)] demonstrates that the formation of the union itself may have an impact on the outside nation's desirability of entry because monetary policy in the monetary union nation's will change. Finally, I also ignore savings in transactions costs, which was used to make the initial argument for welfare enhancements from joining a monetary union [Mundell [14, (1961)]]. My motivation for concentrating on the implications of differences in market power is that this distinction is likely to be particularly important in the decision of an outside country choosing whether

\footnotetext{
${ }^{3}$ See, for example, Bayoumi [4, (1994)] and Canzoneri and Rogers [9, (1990)] for formal treatments of optimal currency area issues and Bayoumi and Eichengreen [5, (1993)] for an empirical assessment of Europe as an optimal currency area. Alesina and Grilli [2, (1993)] examine the implications of optimal currency area arguments for a multi-speed EMU.
} 
or not to join an existing monetary union.

This paper is divided into 4 sections. Section 2 introduces the basic model and derives the equilibrium rates of depreciation chosen by the outside country and the existing monetary union with the outside country independent and with the outside nation joining the monetary union. Section 3 introduces explicit functional forms to allow for comparison between the two regimes. Section 4 concludes.

\section{Basic model}

\subsection{Central bank decisions with the outside country independent}

In this section, I derive the central bank decisions with the outside country independent.

Let $y$ represent outside country output and $y^{*}$ the output of the monetary union. I assume a very reduced form for the aggregate supply function. Output is assumed to be a function of the change in the regime's nominal exchange rate, $\Delta e$ and $\Delta e^{*}$ respectively, and the regime's terms of trade, $p$ and $p^{*}$ respectively. ${ }^{4}$

$$
\begin{gathered}
y=y(\Delta e, p) \\
y^{*}=y^{*}\left(\Delta e^{*}, p^{*}\right)
\end{gathered}
$$

where $X_{\Delta e}>0, X_{p}>0, X=y, y^{*}$. Consider the nominal exchange rate as that which holds relative to another country, such as the United States.

\footnotetext{
${ }^{4}$ An aggregate supply function of this type can be derived in a rational expectations model with wages contracted one period in advance. For example, see Rogoff [17, (1985)].
} 
The outside country is small relative to the rest of the world, so that $p$ and $p^{*}$ are independent of $y$. However, the monetary union is assumed to be large such that $p$ and $p^{*}$ are functions of $y^{*}$. I assume that the outside country is a competitor of the countries in the existing union, such that $p_{y^{*}}^{*}<0$ and $p_{y^{*}}<0$.

When the outside country is not part of the monetary union, both central banks are assumed to play Cournot relative to each other, i.e. take the other's monetary policy decisions as given. I assume that both the monetary union and the outside country central banks have loss functions which are quadratic in output and nominal exchange rate depreciation which satisfy

$$
£^{*}=\left(y^{*}-\widetilde{y}^{*}\right)^{2}+\Psi^{*}\left(\Delta e^{*}\right)^{2}
$$

for the monetary union and

$$
£=(y-\widetilde{y})^{2}+\Psi(\Delta e)^{2}
$$

for the outside country.

The first-order conditions for the two central banks playing Cournot satisfy

$$
\begin{gathered}
\Delta e^{*}=\frac{\left(\widetilde{y}^{*}-y^{*}\right)}{\Psi^{*}}\left(\frac{y_{\Delta e^{*}}^{*}}{1-p_{y^{*}}^{*} y_{p^{*}}^{*}}\right) \\
\Delta e=\frac{(\widetilde{y}-y)}{\Psi}\left(y_{\Delta e}\right)
\end{gathered}
$$

where the second bracketed terms represent the comparative statics for $d y / d \Delta e$ and $d y^{*} / d \Delta e^{*}$, which are derived in the appendix.

Both countries choose a higher rate of depreciation the higher is the gap between actual and desired income levels, $(\widetilde{y}-y)$, and the lower is the central banks' aversion to inflation, $\Psi$. In addition, the monetary union's exchange rate decision 
reflects the adverse terms of trade effect, which lowers the responsiveness of output to a given nominal exchange rate depreciation. This reduces the amount of depreciation chosen by the monetary union.

\subsection{Central bank decisions with the outside country joining an ex- panded monetary union}

I next turn to the case where the outside country joins the monetary union. Let $\Delta \widehat{e}$ represent the nominal exchange rate depreciation chosen with the outside country included in the monetary union. As discussed above, I assume that the outside country has a "voice" in the monetary union in the sense that the loss function of the central bank of the monetary union inclusive of the outside country is a weighted average of the loss function of previous union members and the outside country

$$
\widehat{£}=\varphi £+(1-\varphi) £^{*}
$$

where $\varphi$ is an exogenous parameter $0<\varphi<1$ which reflects the weight placed on the loss function of the outside country by the monetary union. Substituting from equations (2.3) and (2.4) above and rearranging terms yields

$$
\widehat{£}=\varphi(y-\widetilde{y})^{2}+(1-\varphi)\left(y^{*}-\widetilde{y}^{*}\right)^{2}+\widehat{\Psi}(\Delta \widehat{e})^{2}
$$

where $\widehat{\Psi}$ represents the aversion of the expanded monetary union central bank to inflation

$$
\widehat{\Psi}=\varphi \Psi+(1-\varphi) \Psi^{*}
$$


The first order condition of the expanded monetary union central bank satisfies

$$
\Delta \widehat{e}=\frac{\left[\varphi(\widetilde{y}-y)\left(y_{\Delta \widehat{e}}+y_{p} p_{y^{*}} y_{\Delta \widehat{e}}^{*}\right)+(1-\varphi)\left(\widetilde{y}^{*}-y^{*}\right) y_{\Delta \widehat{e}}^{*}\right]}{\widehat{\Psi}\left(1-p_{y^{*}}^{*} y_{p^{*}}^{*}\right)}
$$

where the second bracketed terms represent the comparative statics for $d y / d \Delta \widehat{e}$ and $d y^{*} / d \Delta \widehat{e}$, which are again derived in the appendix.

The impact of the outside country joining monetary union on monetary policy can be seen by comparing equation (2.9), the first-order condition for the expanded monetary union, with equations (2.5) and (2.6), the first-order conditions for the original monetary union central bank and the independent outside country central bank respectively.

Comparing equation (2.5) and the first term in equation (2.9), the latter has an extra term reflecting the monetary unions' weighted incorporation of the loss function of the central bank of the outside nation. This reflects the degree to which the monetary union internalizes the effects of its monetary policy on the outside nation subsequent to its entry. Since the outside country is a competitor, this term is negative and reduces the rate of depreciation chosen by the monetary union subsequent to entry. Of course, the magnitude of this effect depends on $\varphi$, the degree to which the monetary union gives the outside country a "voice" in monetary policy.

The second term in equation (2.9) also differs slightly with equation (2.6). This term captures the adverse terms of trade effect of a nominal exchange rate depreciation for the expanded union as a whole on the output of the outside country, which is incorporated by the expanded monetary union.

It is interesting to contrast the result in equation (2.9) with the well-known results concerning monetary union found by Rogoff [17, (1985)]. In Rogoff's 
model, the creation of monetary union eliminated the adverse real exchange rate effects of monetary expansion. A country independently pursuing a monetary expansion would see that expansion partially offset by the adverse effect its output expansion would have on its terms of trade. However, if that country's output expansion was accommodated by a monetary expansion by its union partner, this effect would be mitigated. Holding all else equal, this could lead central banks to choose larger monetary expansions in Rogoff's model. However, a significant characteristic of the current model is that even though the outside country is assumed to be small in the sense of lacking market power in trade, it is given a non-zero weight in the determination of monetary policy in the expanded union. Because the outside country is small in the current model, its entry into the monetary union has no effect on the terms of trade impact of a monetary expansion by the union. Therefore, the accommodation considered by Rogoff does not enter here.

\section{Specific functional form}

\subsection{Benchmark linear case}

Because joining the union entails a discrete rather than a continuous change, gauging the impact of the outside country's joining the monetary union is difficult without the adoption of specific functional forms. In this section I adopt such functional forms and examine the implications of the outside country joining the monetary union.

I consider a simple linear example. To focus on the implications of union between nations with different monetary policies, I assume that all characteristics of 
the outside country and the existing members of the monetary union are symmetric with the exception of the differences between the outside nation central bank and the central banks of the existing monetary union. In addition, to make the differences between the central banks one-dimensional, I set $\Psi=\Psi^{*}=\widehat{\Psi}$, so that the outside nation only differs from the central banks of the existing monetary union in its concept of the "output gap," i.e. the degree to which its desired income level exceeds autonomous income.

Let the terms of trade of both the existing monetary union and the outside country be linear in the output of the existing monetary union

$$
\begin{gathered}
p^{*}=\bar{p}^{*}-\gamma y^{*} \\
p=\bar{p}-\gamma y^{*}
\end{gathered}
$$

where $\gamma \epsilon(0,1]$. As above, I let the output of the monetary union and the outside country be linear in their own nominal exchange rate and the price of their output

$$
\begin{gathered}
y=c+\theta \Delta e+\delta p \\
y^{*}=c^{*}+\theta \Delta e^{*}+\delta p^{*}
\end{gathered}
$$

where $\delta \epsilon(0,1]$. Substituting, I obtain

$$
y^{*}=\bar{y}^{*}+\left(\frac{\theta}{1+\delta \gamma}\right) \Delta e^{*}
$$

where $\bar{y}^{*}$ represents the value of output in the monetary union which would prevail if its nominal exchange rate was held constant

$$
\bar{y}^{*}=\frac{c^{*}+\delta \bar{p}^{*}}{1+\delta \gamma}
$$


and

$$
y=\bar{y}+\theta \Delta e-\delta \gamma\left(\frac{\theta}{1+\delta \gamma}\right) \Delta e^{*}
$$

where $\bar{y}$ represents the value of output in the outside country which would prevail if both nominal exchange rates were held constant

$$
\bar{y}=c+\delta \bar{p}-\delta \gamma \bar{y}^{*} .
$$

Substituting (3.5) and (3.6), into (2.5) and (2.6), $\Delta e^{*}$ and $\Delta e$ prior to entry by the outside nation satisfy

$$
\Delta e^{*}=\left[\frac{(1+\delta \gamma) \theta}{(1+\delta \gamma)^{2} \Psi+\theta^{2}}\right]\left(\widetilde{y}^{*}-\bar{y}^{*}\right)
$$

and

$$
\Delta e=\left(\frac{\theta}{\Psi+\theta^{2}}\right)\left[(\widetilde{y}-\bar{y})+\left(\frac{\delta \gamma \theta}{1+\delta \gamma}\right) \Delta e^{*}\right]
$$

I next turn to the solution for the equilibrium after the outside country joins the monetary union. Note that by (3.5) and (3.6)

$$
\frac{d y}{d \Delta e}>\frac{d y}{d \Delta \widehat{e}}=\frac{d y^{*}}{d \Delta \widehat{e}}=\frac{d y^{*}}{d \Delta e^{*}}
$$

The first relationship is intuitive. Output in the outside country is more responsive to a nominal exchange rate depreciation when it is independent because a change in $\Delta \widehat{e}$ within the monetary union has the adverse impact of increasing the output of the existing monetary union.

The equivalence of $d y / d \Delta \widehat{e}$ and $d y^{*} / d \Delta \widehat{e}$ is attributable to the assumption that $\gamma$ is equal across countries, which implies that expanded monetary union output has an identical negative terms of trade impact on the outside nation as on the existing monetary union. Substituting (3.5) and (3.6) into (2.9) I obtain 


$$
\Delta \widehat{e}=\left[\frac{(1+\delta \gamma) \theta}{(1+\delta \gamma)^{2} \Psi+\theta^{2}}\right] \widehat{y}
$$

where

$$
\widehat{y}=\left[\varphi(\widetilde{y}-\bar{y})+(1-\varphi)\left(\widetilde{y}^{*}-\bar{y}^{*}\right)\right]
$$

We can now compare the equilibrium exchange rate depreciations with the outside member independent and entering the monetary union. By equations (3.7) and (3.10) we obtain

$$
\frac{\Delta e^{*}}{\Delta \widehat{e}}=\frac{\left(\widetilde{y}^{*}-\bar{y}^{*}\right)}{\widehat{y}}
$$

This leads to our first proposition:

PROPOSITION 1: $\Delta \widehat{e} \leq \Delta e^{*}$ if and only if $(\widetilde{y}-\bar{y}) \leq\left(\widetilde{y}^{*}-\bar{y}^{*}\right)$.

The proof of proposition 1 follows directly from equations (3.11) and (3.12). The sign of the difference between $\Delta \widehat{e}$ and $\Delta e^{*}$ depends on the difference in perceived "output gaps" of the central banks of the outside country and the existing union members. Proposition 1 implies that entry by the outside nation can result in a reduction in the rate of depreciation among the existing monetary union if the outside country central bank is more "inflation averse" than the central banks of the existing union members, i.e. if its perceived output gap is smaller.

Whether the rate of exchange rate depreciation goes up or down, the magnitude of the change in the rate of depreciation is proportional to $\varphi$, the weight placed on the loss function of the outside country subsequent to its entry into the monetary union. The impact of joining the monetary union therefore is also 
dependent on the share of the outside country in the decision-making process of the enlarged monetary union.

Second, by equations (3.8) and (3.10)

$$
\frac{\Delta e}{\Delta \widehat{e}}=\xi\left[\left[\theta^{2}+\Psi(1+\delta \gamma)^{2}\right]\left[\frac{(\widetilde{y}-\bar{y})}{\widehat{y}}\right]+\delta \gamma \theta^{2}\left[\frac{\left(\widetilde{y}^{*}-\bar{y}^{*}\right)}{\widehat{y}}\right]\right]
$$

where

$$
\xi \equiv(1+\delta \gamma)\left(\Psi+\theta^{2}\right)
$$

Both terms in equation (3.13) are positive. Therefore a sufficient, but not necessary, condition for $\Delta \widehat{e} \leq \Delta e$ if $(\widetilde{y}-\bar{y}) \geq\left(\widetilde{y}^{*}-\bar{y}^{*}\right)$ is that the first term is greater than one. This condition is satisfied as long as the central bank is sufficiently averse to inflation; a sufficient, but not necessary condition is $\Psi>\theta^{2}$. This leads to the second proposition

PROPOSITION 2: Given $\Psi>\theta^{2}$, if $(\widetilde{y}-\bar{y}) \geq\left(\widetilde{y}^{*}-\bar{y}^{*}\right)$ then $\Delta e>\Delta \widehat{e}$.

The proof follows directly from equation (3.13). Proposition 2 implies that given the parameter restriction, if the outside nation is less inflation-averse than the members of the existing monetary union the outside nation will experience a reduction in its rate of depreciation subsequent to entry into the monetary union. ${ }^{5}$

Taken on their own, propositions 1 and 2 do not accommodate mutuallydesirable entry by the outside nation into the monetary union. Proposition 2

\footnotetext{
${ }^{5}$ While the parameter restriction is innocuous given that the coefficient on the income gap in the loss function of both central banks is specified as equal to one, it should be stressed that this restriction is far stricter than necessary. I use the sufficient condition because the necessary one is analytically quite cumbersome. Moreover, the conditions are specific to the chosen funcitonal forms.
} 
implies that the outside country would gain from entry into a monetary union whose members were more risk-averse than the outside nation. However, Proposition 1 implies that the existing members of the monetary union would refuse entry to such an outside country.

The conditions for mutually-desirable entry must therefore be that the outside member is more inflation-averse than the existing union members, but not so inflation-averse that it would lose from entry into the union. The conditions for such a mutually-desirable union entry are delineated in Proposition 3:

PROPOSITION 3: Entry by the outside nation into the existing monetary union is mutually desirable if

$$
\frac{\left(\widetilde{y}^{*}-\bar{y}^{*}\right)}{\widehat{y}} \geq \frac{(\widetilde{y}-\bar{y})}{\widehat{y}} \geq \tau
$$

where $\tau$ is a constant term which satisfies

$$
\tau \equiv \frac{(1-\varphi)\left[(1+\delta \gamma) \Psi+\theta^{2}\right]-(\delta \gamma)^{2} \theta^{2}}{(1-\varphi)\left[(1+\delta \gamma) \Psi+\theta^{2}\right]+(\delta \gamma)^{2}\left[(1-\varphi)(1+\delta \gamma) \Psi-\varphi \theta^{2}\right]}
$$

Proposition 3 can be proven in two steps. First, given $(\widetilde{y}-\bar{y}) \leq\left(\widetilde{y}^{*}-\bar{y}^{*}\right)$, i.e. that the outside nation is more inflation-averse than the existing union members, Proposition 1 indicates that the existing union members will be willing to allow entry because it will reduce their rate of depreciation.

Second, a mutually-desirable union requires the outside member to also benefit from entry. This requires that the degree to which the outside nation is more inflation-averse than the existing union members can not be too large. By equations (3.8), (3.7), and (3.10), $\Delta \hat{e} \leq \Delta e$ requires 


$$
\frac{(\widetilde{y}-\bar{y})}{\widehat{y}} \geq \tau
$$

where $\tau$ is defined as above. This represents the lower-bound value of $(\widetilde{y}-\bar{y}) / \widehat{y}$ which leaves the entering nation with a lower rate of depreciation subsequent to joining the union.

Since $\varphi<1$, it is easy to verify that the right-hand term is less than one. This implies that under the proper parameter values, mutually-desirable entry by an outside nation into an existing monetary union is feasible. These conditions require that the outside nation is more inflation-averse than the average of the existing members of the monetary union, but not too much more. If the inflation bias of the outside nation central bank is sufficiently lower than that of the existing monetary union, the outside nation will be better off on its own.

\section{Conclusion}

When joining an existing monetary union, an individual outside nation is likely to be small relative to the existing union as a whole. This paper examines the implications of this characteristic for the impact of the outside country joining the monetary union on changes in the prevailing rates of depreciation within the outside country and the monetary union. Our results demonstrate that this disparity in market power can play a role in allowing both the outside nation and the existing monetary union to experience a decline in its depreciation rate subsequent to entry by the outside country. consequently, the disparity in market power between the small outside country and the large existing monetary union can facilitate mutually-desirable entry by the outside nation into the monetary 
union.

In particular, our results identify two characteristics necessary for mutuallydesirable entry by the outside nation. First, the outside nation must be more inflation-averse than the central bank of the existing monetary union. Since the outside nation is small, violation of this condition would imply that the rate of exchange rate depreciation in the existing monetary union would rise after its entry. Second, the outside nation must be sufficiently similar in its attitude towards inflation. In particular, if the outside nation is too inflation averse relative to the central bank of the existing monetary union it would do better in terms of reduced exchange rate depreciation rates if it remained outside the monetary union.

It is interesting to contrast the results above with well-known results in the literature. First, consider the problems associated with differences in desired monetary policies, such as in Casella [10, (1992)]. When countries have diverging monetary policy goals, Casella [10, (1992)] demonstrates that a small country would demand a greater-than-proportionate voice in a resulting monetary union. Since it is impossible for all countries to have a greater-than-proportionate voice, her analysis concludes that unions cannot be sustained without credible punishment schemes. However, with our incorporation of the credibility implications of joining a union, we find that sustainable unions may exist if the outside and existing members possess the proper characteristics.

In addition, the analysis raises the potential for a feasible "multi-speed" union: An outside nation with relatively desirable inflation characteristics who was unwilling to join a smaller monetary union may be willing to join a larger existing union if the increase in union size implies an increase in the terms-of-trade deter- 
rence to inflation. This possibility contrasts with earlier literature, such as Alesina and Grilli [2, (1993)] who shed doubt on the feasibility of multi-speed monetary unions. 


\section{Appendix}

With the outside country independent, totally differentiating the equations above yields

$$
\begin{gathered}
d y-y_{\Delta e} d \Delta e-y_{p} d p=0 \\
d y^{*}-y_{\Delta e^{*}}^{*} d \Delta e^{*}-y_{p^{*}}^{*} d p^{*}=0 \\
d p^{*}-p_{y^{*}}^{*} d y^{*}=0 \\
d p-p_{y^{*}} d y^{*}=0
\end{gathered}
$$

The comparative statics satisfy

$$
\begin{gathered}
\frac{d y}{d \Delta e^{*}}=\frac{y_{p} p_{y^{*}} y_{\Delta e^{*}}^{*}}{1-y_{p^{*}}^{*} p_{y^{*}}^{*}} \\
\frac{d y^{*}}{d \Delta e^{*}}=\frac{y_{\Delta e^{*}}^{*}}{1-y_{p^{*}}^{*} p_{y^{*}}^{*}} \\
\frac{d y}{d \Delta e}=y_{\Delta e} \\
\frac{d y^{*}}{d \Delta e}=0
\end{gathered}
$$

The system of equations for the expanded monetary union is the same, except that $\Delta \hat{e}$ is substituted for both $\Delta e$ and $\Delta e^{*}$. The comparative statics of the system then satisfy

$$
\begin{gathered}
\frac{d y}{d \Delta \widehat{e}}=\frac{y_{\Delta \widehat{e}}+y_{p} p_{y^{*}} y_{\Delta e^{*}}^{*}}{1-y_{p^{*}}^{*} p_{y^{*}}^{*}} \\
\frac{d y^{*}}{d \Delta \widehat{e}}=\frac{y_{\Delta \widehat{e}}^{*}}{1-y_{p^{*}}^{*} p_{y^{*}}^{*}}
\end{gathered}
$$




\section{References}

[1] Alesina, Alberto and Vittorio Grilli (1991), "The European Central Bank: Reshaping Monetary Policy in Europe, in M. Canzoneri and V.Grilli eds., Establishing a Central Bank (CEPR-Cambridge University Press, Cambridge).

[2] Alesina, Alberto and Vittorio Grilli (1993), "On the Feasibility of a OneSpeed or Mullti-speed European Monetary Union," Economics and Politics, 5, no. 2, 145-165.

[3] Barro, Robert and David Gordon, "(1983), "Rules, Discretion, and Reputation in a Model of Monetary Policy," Journal of Monetary Economics, 12, $101-122$.

[4] Bayoumi, Tamim (1994), "A Formal Model of Optimum Currency Areas," International Monetary Fund Staff Papers, 41 (December), 537-554.

[5] Bayoumi, Tamim and Barry Eichengreen (1993), "Shocking Aspects of European Monetary Union," in Torres, Francisco F. and Francesco Giavazzi eds., The Transition to Economic and Monetary Union, Cambridge University Press, Cambridge, 193-240.

[6] Bean, Charles R. (1992), "Economic and Monetary Union in Europe," Journal of Economic Perspectives, 6, no. 4 (Fall), 31-52.

[7] Bergin, Paul and Mathias Moersch (1997), European Monetary Union: Transition, International Impact and Policy Options, Welfens, J.J. ed., SpringerVerlag, Berlin. 
[8] Canzoneri, Matthew B. and Dale W. Henderson (1991), Monetary Policy in Interdependent Economies, MIT Press, Cambridge MA.

[9] Canzoneri, Matthew B. and Carol A. Rogers (1990), "Is the European Community an Optimal Currency Area?: Optimal Taxation Versus the Cost of Multiple Currencies," American Economic Review, 80, no. 3, 419-433.

[10] Casella, Alessandra (1992), "Participation in a Currency Union," American Economic Review, 82, no. 4, 847-863.

[11] Chang, Roberto (1995), "Bargaining a Monetary Union," Journal of Economic Theory, 66, no. 1 (June), 89-112.

[12] Cooper, Russell, and Hubert Kempf (1998), "On the Gains to Monetary Union," mimeo.

[13] Lane, Philip R., "Inflation in Open Economies," Journal of International Economics, 42, 327-347.

[14] Mundell, Robert A., "A Theory of Optimal Currency Areas," American Economic Review, 51, 657-665.

[15] Martin, Philippe (1995), "Free-Riding, Convergence and Two-Speed Monetary unification in Europe," European Economic Review, 39, 1345-1364.

[16] Obstfeld, Maurice (1997), "Europe's Gamble," Brookings Papers on Economic Activity, 2, 241-300.

[17] Rogoff, Kenneth (1985), "Can International Monetary Policy Coordination be Counterproductive?," Journal of International Economics, 18 (May), 199217. 
[18] Wyplosz, Charles (1997), "EMU: Why and How It Might Happen," Journal of Economic Perspectives, 11, no. 4 (Fall), 3-22. 